\title{
CAMINHOS SINUOSOS: OS DESLIZES NOS ESTUDOS EM ADMINISTRAÇÃO PÚBLICA E DE EMPRESAS
}

SINUOUS WAYS: COMMON MISTAKES IN STUDIES ON PUBLIC AND BUSINESS ADMINISTRATION IN BRAZIL

\section{BRENO DE PAULA ANDRADE CRUZ brenocruz@yahoo.com.br}

Universidade Federal Rural do Rio de Janeiro

\section{STEVEN DUTT ROSS}

Universidade Federal do Estado do Rio de Janeiro

\section{RESUMO}

Este ensaio discute sobre 13 deslizes comuns encontrados em estudos no campo de Administração Pública e de Empresas no Brasil, agregando-os em três dimensões. A primeira dimensão, "Deslizes por Falta de Reflexão", inclui deslizes por falta de reflexão dos autores, como, por exemplo, usar a palavra Metodologia na seção que discute Método; ou autores economizarem em palavras para apresentar a relevância do trabalho. Já na segunda dimensão, "Deslizes na Utilização do Método", discutimos aspectos referentes ao Método em um trabalho científico, deixando claro, por exemplo, alguns erros cometidos, tais como nomear um Método (Netnografia) e, na prática, usar outro (Observação Não Participante). A terceira dimensão, "Deslizes no Sentido de Fazer Ciência", apresenta os deslizes relacionados à relevância de um texto ao fazer Ciência. Por exemplo, um texto que não apresenta implicações gerenciais e teóricas no campo da Administração Pública e de Empresas ou que não discute questões para futuras pesquisas deixa a desejar no sentido de ser relevante para a Ciência e para as organizações.

Palavras-chave: Prática em Pesquisa em Administração. Deslizes na Prática da Pesquisa. Método.

\begin{abstract}
This essay aims to examine 13 common mistakes identified in studies in the field of Public and Business Administration in Brazil, grouped into three dimensions. The first dimension, "Slips for Lack of Reflection", includes those mistakes related to the lack of reflection by the authors, such as when using the word methodology in the section that discusses the methods or using words sparingly to present the relevance of the research. In the second dimension, "Slips in the Use of the Method", we discuss aspects related to the method in a scientific paper, making clear, for example, some mistakes generally made when naming one given Method (Netnography) and applying another instead (Non-Participant Observation). The third dimension, "Slips in the Sense of Production of Scientific Studies", presents mistakes related to the relevance of a text to produce science. For instance, a text that does not have managerial and theoretical implications in the field of Public and Business Administration or even that does not discuss issues for future research is far from being relevant to science and organizations.

Keywords: Research Practice in Management. Slips on Research Practice. Methods.
\end{abstract}




\section{NOSSAS MOTIVAÇÕES}

Quando em uma mesa de bar um pesquisador quali-quanti em Administração junta-se a um estatístico que atua como professor no Campo de Públicas e Administração de Empresas, impreterivelmente, a discussão toma um caminho: os deslizes frequentes encontrados nos trabalhos publicados na área de Administração Pública e de Empresas no contexto brasileiro - seja em periódicos ou em anais de eventos. E, se sua preocupação, enquanto leitor, neste primeiro parágrafo, encontra-se nesta narrativa pessoal destacando o locus da nossa motivação na construção deste texto, (i) a mesa de bar tem sido um espaço de discussão científica e do "fazer pesquisa", conforme aponta Spink (2008) em sua discussão sobre microlugares e Ciência; e, (ii) Piacentini (2008) discute o crescimento do uso da primeira pessoa nas publicações acadêmicas no Campo de Ciências Sociais e Humanas.

A discussão polarizada que muitas vezes ocorre entre defensores românticos, de um lado, da pesquisa qualitativa, e, de outro lado, da pesquisa quantitativa, acaba por negligenciar uma possibilidade para esses indivíduos, esbarrando em outra dicotomia, porém, de ordem epistêmica: o Positivismo versus Antipositivismo. E essa discussão teórica no Campo da Administração Pública e de Empresas já foi e tem sido conduzida por alguns estudiosos, como, recentemente, por Paes de Paula (2016). Embora pareça difícil um diálogo entre tais paradigmas, a própria proposta do Antipositivismo, ao sugerir a não existência de regras, no nosso entendimento, possibilita a triangulação de métodos e técnicas das pesquisas qualitativa e quantitativa.

O paradigma aqui adotado, conforme nossas experiências enquanto pesquisadores, é Positivista - e esse posicionamento nada mais é do que um reflexo da tradição Positivista das pesquisas em Administração, segundo apontam Carton e Mouricou (2017, p. 173). Assim, no decorrer dos anos, especialmente entre 2013 e 2016, como professores e avaliadores de periódicos e congressos na área de Administração Pública e de Empresas, conseguimos constatar alguns deslizes frequentes encontrados em trabalhos da área, principalmente naqueles de congressos científicos. Há de se constatar 
que geralmente trabalhos submetidos a congressos ainda estão em construção; mas, mesmo assim, existem deslizes às vezes inaceitáveis para o "fazer ciência".

Talvez, esses erros sejam reflexo de uma academia que tem sofrido com as pressões dos órgãos de controle como a Capes; ou, em pior direção, uma questão ética ao delegar aos alunos e alunas de pós-graduação a responsabilidade de publicar. Como apontam Bispo e Costa (2016), parece haver um aumento do volume de artigos produzidos por alunos de pós-graduação como instrumento de avaliação em disciplinas de mestrado e doutorado. Vizeu, Macadar e Graeml (2016, p. 984) asseveram que a “[...] valorização quantitativa da produção sem consideração da qualidade do trabalho acadêmico" é uma realidade no país.

Especificamente com relação à pós-graduação, alguns textos têm discutido tanto a "forma do fazer" como a questão do produtivismo acadêmico. No tocante à "forma do fazer", Ferreira, Canela e Pinto (2014) discutem o processo de editoração para que alunos de pós-graduação stricto sensu entendam o processo; e que, assim, eles possam ter maior familiaridade e posterior sucesso na submissão de seus textos. Já Cota, Ikeda e Sbragia (2008) associam o processo de elaboração de uma dissertação ou tese às teorias relacionadas à gestão de projetos. Na nossa percepção, os dois estudos buscam indiretamente preparar alunos de pós-graduação para a cruel lógica de atendimento da pressão do produtivismo acadêmico em Administração Pública e de Empresas.

Patrus, Dantas e Shigaki (2015) destacam que o aumento do produtivismo acadêmico pode gerar a falta de qualidade nos textos publicados e o aumento de uma possível falta de solidariedade entre os pares no processo de revisão. Além disso, esse controle da Capes reforça, no nosso entendimento, avaliações esquizofrênicas pautadas num processo de padronização que reconhece apenas (i) aquilo que é disciplinar, rejeitando o interdisciplinar; (ii) a adequação às normas de submissão de um congresso ou de um periódico; ou (iii) uma tendência prévia de rejeição de textos que fogem daquilo que é a forma padrão de apresentar textos científicos em Administração Pública e de Empresas. 
Além desse viés crítico do contexto da academia brasileira em função de um órgão regulador, há também uma importante discussão do "how to do" na literatura internacional. Não faltam trabalhos que discutem caminhos e estratégias para tornar as pesquisas em Administração mais interessantes (SHUGAN, 2003; BARLEY, 2006; BARTUNEK; RYNES; IRELAND, 2006; DAS; LONG, 2010; CARTON; MOURICOU, 2017). Essas contribuições são diversas e perpassam (i) a elaboração do problema de pesquisa e como torná-lo mais atraente para avaliadores e leitores (VOSS, 2003); numa perspectiva crítica, como acadêmicos em Administração podem conduzir pesquisas e definir problemas menos irrelevantes (GARMAN, 2011); (iii) o que considerar na forma e no processo de comunicação nos artigos (DAFT, 1983); (iv) a importância de refletir nas contribuições de uma pesquisa para a prática gerencial (RYAN, 1977), entre outras preocupações.

Nossas motivações, de certa maneira, consideram esses aspectos apresentados no parágrafo anterior, além de outros apontamentos que são neste ensaio discutidos. Nossa conversa inicial, à mesa de bar, apontou-nos deslizes presentes em muitos trabalhos tanto quantitativos quanto qualitativos. Deixamos o guardanapo de lado para anotar nossas inquietações e usamos o bloco de nota dos nossos celulares. Assim, apresentamos, neste ensaio teórico, três dimensões que agregam aquilo que consideramos como deslizes de pesquisadores(as) no nosso campo: (i) dimensão "Falta de Reflexão" - que identifica ocorrências a partir da reflexão do uso de termos, base teórica ou economia de informações que ajudem a contextualizar o estudo; (ii) dimensão "Utilização do Método" - que apresenta deslizes relacionados ao uso não robusto de alguns métodos nas pesquisas qualitativa e quantitativa; e, (iii) dimensão "Sentido do Fazer Ciência" - que problematiza a falta de implicações de um estudo na sociedade e na área de conhecimento. A Figura 1 sistematiza essas três dimensões e os 13 deslizes identificados a partir da nossa reflexão, enquanto pesquisadores da área de Administração Pública e de Empresas. 
Figura 1 Sistematização das dimensões a partir dos deslizes identificados pelos autores

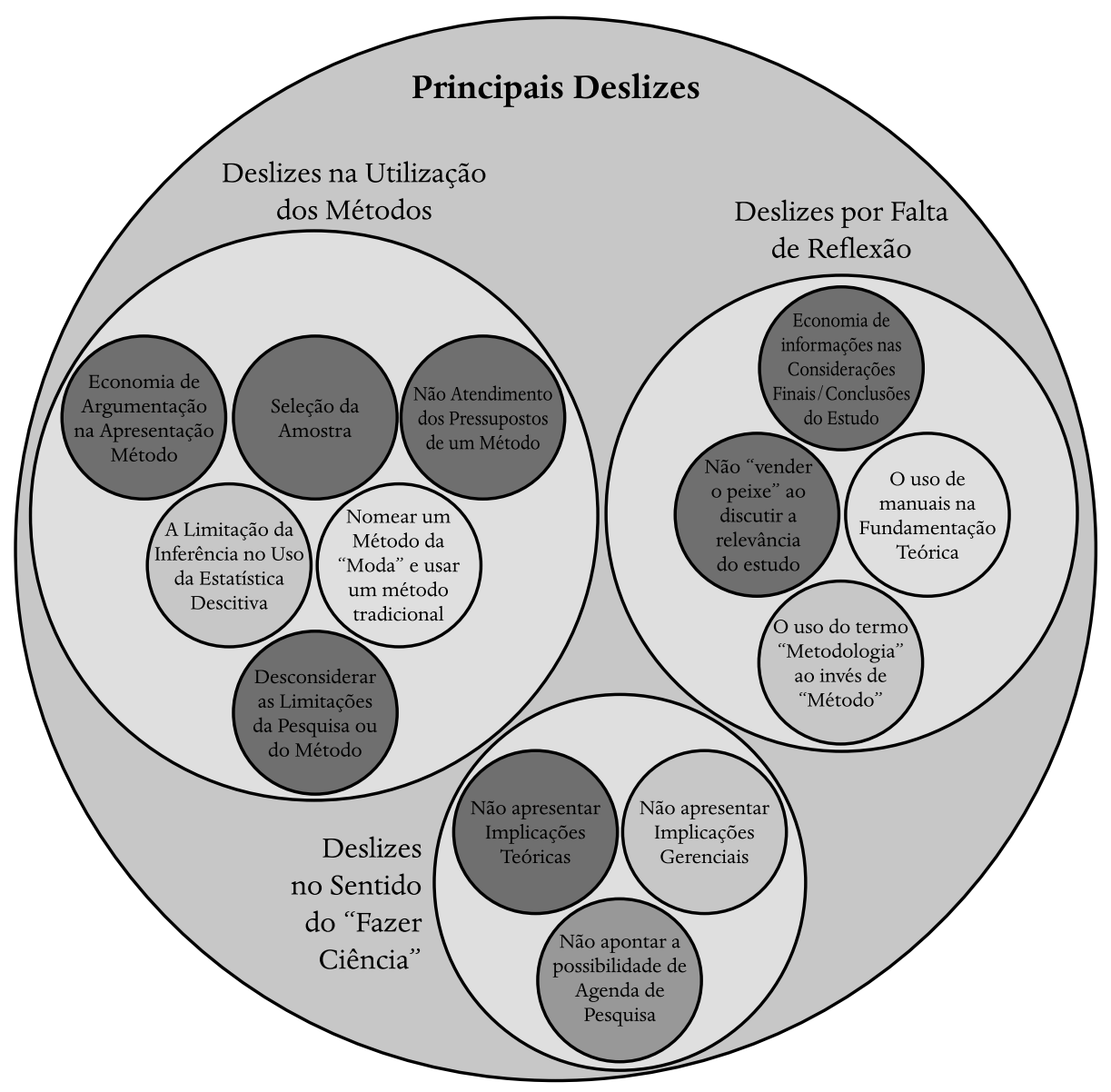

Fonte: Elaborado pelos autores por meio do software R.

Neste ensaio teórico, apresentamos essas três dimensões em cada seção que segue, na última seção, finalizamos nossa discussão. Quando discutimos deslizes, não nos referimos a erros, pois entendemos que o termo "erro" poderia gerar desconforto e ser muito pragmático. Assim, o termo "deslize" parece mais suave, visto que nossa forma de entender e conduzir pesquisas científicas pode ser diferente de outros(as) pesquisadores(as). 
Todavia, pautados na discussão teórica realizada em periódicos nacionais e internacionais na área de Administração Pública e de Empresas, entendemos que os 13 deslizes aqui apresentados podem ser considerados em novos estudos no sentido de maximizar atributos na apresentação de um artigo a um periódico.

Desta maneira, entendemos como relevante este ensaio em função de algumas razões. A primeira delas constrói-se a partir de uma análise, em contexto brasileiro, de possibilidades de reflexão sobre deslizes comuns na prática da pesquisa acadêmica no campo de Administração Pública e de Empresas. Embora a reflexão gere desconforto, consideramos ser relevante discutir os deslizes aqui apresentados. O segundo aspecto que torna esse trabalho relevante para um público jovem que inicia na prática da pesquisa em Administração Pública e de Empresas é o estilo de comunicação aqui proposto, corroborando os argumentos de DeNisi (1994) e Carton e Mouricou (2017) sobre a necessidade de uma escrita acadêmica mais acessível. E, como terceiro aspecto, colocamos que o conteúdo deste ensaio pode servir como fonte de informações em preparação de futuros textos por pesquisadores iniciantes que desconhecem os deslizes aqui discutidos. Na próxima seção, discutimos sobre os Deslizes por Falta de Reflexão por parte dos autores de textos.

\section{DESLIZES POR FALTA DE REFLEXÃO}

Ao identificar 13 deslizes, verificamos que quatro deles (i) "Não vender o peixe" ao discutir a Relevância do Estudo, (ii) $\mathrm{O}$ uso do termo "Metodologia" ao invés de "Método", (iii) O uso de manuais na Fundamentação Teórica, e (iv) Economia de Informações nas Considerações Finais/Conclusões do Estudo são resultado da falta de reflexão por parte de autores(as). A falta de reflexão é entendida aqui como uma limitação de autores(as) no processo de apresentação de um relatório de pesquisa que negligencia alguns aspectos. Por exemplo, utilizar o termo "Metodologia" ao invés de "Método" é uma limitação com relação ao processo de reflexão de autores(as), visto que a simples análise da palavra Metodologia revelaria, a partir do seu sufixo "logia", o estudo de algo - neste caso, dos métodos. 
Assim, esses quatro deslizes aqui discutidos nesta dimensão parecem existir nos trabalhos no campo de Administração Pública e de Empresas em função de reflexões basilares na apresentação de uma comunicação científica em nosso campo.

Embora nos gere certo desconforto expor e apontar deslizes em trabalhos de terceiros, nós mesmos já cometemos alguns dos deslizes aqui apresentados em artigos prévios publicados até em periódicos A2, atendemos às solicitações dos(as) avaliadoras(as) e para cada deslize apresentamos alguns casos empíricos encontrados na literatura em Administração e Administração Pública no Brasil.

\section{NÃO “VENDER O PEIXE" AO DISCUTIR A RELEVÂNCIA DO ESTUDO}

DeNisi (1994, p. 145) aborda uma interessante questão em seu ensaio com relação às contribuições da pesquisa para a prática gerencial: "é a relevância da pesquisa irrelevante?". Embora a narrativa de DeNisi associe o desinteresse dos gestores aos temas e às pesquisas publicadas nos importantes periódicos internacionais em Administração, autoras e autores devem se perguntar sobre a relevância dos seus estudos; seja para a academia, seja para o mercado. Por exemplo, conforme verificado em Cassundé et al. (2017) e Boaventura et al. (2018), entendemos que os autores poderiam explorar de maneira mais explícita a relevância do estudo apresentado à comunidade acadêmica interessada na formação acadêmica em Administração.

No nosso ponto de vista, um estudo relevante em Administração Pública e de Empresas apresenta algumas características fundamentais, tais como: (i) inovação - seja numa perspectiva teórica ao agrupar diferentes teorias e sujeitos, ou numa perspectiva prática ao analisar fenômenos aparentemente distantes das organizações; (ii) implicações teóricas - evidenciar o impacto do estudo na teoria existente ou criar uma teoria; (iii) implicações gerenciais - seja na Administração Pública, com resultados que melhorem o bem-estar do cidadão, seja na Administração de Empresas, maximizando resultados ou minimizando desperdícios; e, (iv) agenda de pesquisa - sugerir e estimular a reflexão para futuras questões de pesquisa relacionadas ao tema, teoria ou objeto estudado. 
Das e Long (2010) consideram que a relevância de um estudo é um dos cinco atributos a serem considerados em bons relatórios de pesquisa publicados na área de Administração, além de outros quatro atributos, quais sejam: comunicação (estilo e forma); rigor (teorização e método); novidade (perspectiva ou maneira de conduzir o estudo); e, validade (amostragem, interpretação e generalização). Entendemos que a forma de comunicação está relacionada à relevância do texto e, nos primeiros parágrafos, os autores devem encontrar estratégias para evidenciar a relevância do estudo, não deixando este tópico somente para as últimas páginas (nas considerações finais).

Assim, o autor tem de "vender o peixe" nos primeiros parágrafos ao deixar claro os impactos do trabalho na literatura e na prática gerencial. Bartunek, Rynes e Ireland (2006) e Barley (2006), em edição especial do Academy of Management Journal, têm uma mesma perspectiva sobre o que faz um artigo ser interessante em Administração: ir por um caminho novo em relação àquilo que tem sido discutido, seja numa perspectiva teórica ou no que diz respeito ao método. E esse olhar novo sobre uma teoria ou pertinente ao método evidencia, na nossa visão, a relevância de um relatório de pesquisa publicado em importantes veículos acadêmicos. Dessa forma, refletir sobre a relevância do texto é explicitar aos leitores(as) e avaliadores(as) as contribuições iniciais de uma pesquisa.

\section{O USO DO TERMO “METODOLOGIA" AO INVÉS DE “MÉTODO"}

Há diferença conceitual entre os termos Metodologia e Método; e autores(as) de diferentes áreas do conhecimento apontam tais diferenças conforme pode ser visualizado no Quadro 1. Mingers (2015) afirma que, muitas vezes, os termos "Método" e "Metodologia" são usados de maneira imprecisa nos estudos científicos. Em um texto convidado para a RAEP, a presidente do Inep, a educadora Maria Inês Fini, aborda inicialmente, na perspectiva histórica e filosófica, a definição de Método. Para a educadora, as discussões sobre Método são de longa data e foram construídas à luz da ideia de um caminho a ser alcançado por meio de passos definidos e claros (FINI, 2018). Todavia a definição de Método confunde-se nos estudos em 
Administração ao ser substituída pela palavra Metodologia, como é possível verificar em alguns estudos publicados em periódicos A2 no Brasil, como os trabalhos de Mascarenhas e Barbosa (2013), Flates, Serra e Martins (2014); e em periódicos B1, como o estudo de Rímoli e Melo (2018).

$\mathrm{Na}$ análise filosófica de "Método", entende-se esse termo como um conjunto de procedimentos e regras organizado que tornará robusta a prática do ato de "fazer pesquisa científica" (COOK; FONOW, 1986; JAPIASSÚ; MARCONDES, 1996; MARTINS, 2004; ABBAGNAMO, 2007). Neste sentido, os métodos contribuem: (i) no detalhamento dos procedimentos gerais do planejamento de uma pesquisa; (ii) no recorte de contextos, variáveis, fenômenos ou sujeitos a serem analisados; (iii) na definição de como relações de causa e efeito devem ser apresentadas; (iv) no entendimento das limitações da pesquisa; (v) na demarcação de escolhas teóricas, empíricas ou subjetivas de variáveis ou sujeitos analisados; e, (vi) ao responder questões gerais dos procedimentos adotados na pesquisa, tais como "por quê?", "como?", "quando?", "onde?” e "quanto?”.

Já o termo "Metodologia" é o estudo de um ou mais métodos (MINGERS, 2015). Conforme problematizam alguns filósofos no contexto brasileiro, é "[ ... ] a ciência ou estudo dos métodos" (JAPIASSÚ; MARCONDES, 1996, p. 182). Assim, se um artigo científico apresentado num periódico não se propõe a fazer uma análise de um ou mais métodos de pesquisa, não é recomendado que se use o termo "Metodologia" no texto. Por isso que as disciplinas em programas de pós-graduação que se propõem a discutir métodos de pesquisa (qualitativos ou quantitativos), geralmente, recebem o nome de "Metodologia de Pesquisa". Dessa maneira, advogamos aqui a necessidade de reflexão no tocante ao uso desses dois termos nas pesquisas em Administração Pública e de Empresas no Brasil, visto que é recorrente o uso do termo "Metodologia" em trabalhos. Inclusive, manuais de orientação a autores de periódicos A2 na área sugerem o uso deste termo. 
Quadro 1 Diferenças entre os termos "Metodologia" e "Método" encontradas na filosofia e em estudos científicos

\begin{tabular}{|c|c|c|}
\hline Autor & Definição de Metodologia & DeFinição de MÉTodo \\
\hline $\begin{array}{l}\text { Martins } \\
(2004, \text { p. } 291)\end{array}$ & $\begin{array}{c}\text { “[...] metodologia é entendida } \\
\text { aqui como o conhecimento crítico } \\
\text { dos caminhos do processo cien- } \\
\text { tífico, indagando e questionando } \\
\text { acerca de seus limites e possibili- } \\
\text { dades (Demo, 1989). Não se trata, } \\
\text { portanto, de uma discussão sobre } \\
\text { técnicas qualitativas de pesquisa, } \\
\text { mas sobre maneiras de se fazer } \\
\text { ciência." }\end{array}$ & $\begin{array}{l}\text { O método direciona o "fazer } \\
\text { ciência", e, especialmente } \\
\text { os métodos qualitativos têm } \\
\text { maior flexibilidade na coleta } \\
\text { de dados, incorporando } \\
\text { técnicas mais adequadas para } \\
\text { cada contexto. }\end{array}$ \\
\hline $\begin{array}{l}\text { Japiassú e } \\
\text { Marcondes } \\
\text { (1996) }\end{array}$ & $\begin{array}{l}\text { “Literalmente, ciência ou estudo } \\
\text { dos métodos. Investigação sobre } \\
\text { os métodos empregados nas dife- } \\
\text { rentes ciências, seus fundamentos } \\
\text { e validade, e sua relação com as } \\
\text { teorias científicas.” (p. 182) }\end{array}$ & $\begin{array}{l}\text { "Conjunto de procedimentos } \\
\text { racionais, baseados em } \\
\text { regras, que visam atingir } \\
\text { um objetivo determinado. } \\
\text { Por exemplo, na ciência, } \\
\text { o estabelecimento e a } \\
\text { demonstração de uma } \\
\text { verdade científica". (p. 181). }\end{array}$ \\
\hline Dick (2015) & \multicolumn{2}{|c|}{$\begin{array}{l}\text { Em relação à pesquisa-ação, por exemplo, é importante realçar } \\
\text { que tal método não pode ser considerado metodologia. }\end{array}$} \\
\hline $\begin{array}{l}\text { Cook e Fonow } \\
\qquad(1986) ; \\
\text { Harding (1987). }\end{array}$ & $\begin{array}{l}\text { Metodologia é o estudo dos mé- } \\
\text { todos, sendo às vezes complexo e } \\
\text { abstrato. }\end{array}$ & $\begin{array}{l}\text { A técnica que se usa para } \\
\text { evidenciar os procedimentos } \\
\text { científicos adotados. }\end{array}$ \\
\hline Mingers (2015) & Estudo dos métodos. & $\begin{array}{l}\text { Confere robustez à } \\
\text { pesquisa por meio de regras } \\
\text { predefinidas. }\end{array}$ \\
\hline $\begin{array}{l}\text { Abbagnamo } \\
\qquad(2007)\end{array}$ & $\begin{array}{l}\text { “[...] disciplina filosófica relativa- } \\
\text { mente autônoma e destinada à } \\
\text { análise das técnicas de investiga- } \\
\text { ção empregadas em uma ou mais } \\
\text { ciências” (p. 669). }\end{array}$ & $\begin{array}{l}\text { “[...] um procedimento de } \\
\text { investigação organizado, re- } \\
\text { petível e autocorrigível. que } \\
\text { garanta a obtenção de resul- } \\
\text { tados válidos” (p. 668). }\end{array}$ \\
\hline
\end{tabular}

Fonte: Elaborado pelos autores. 
O deslize em usar Metodologia ao invés de Método não é uma realidade apenas brasileira do campo de Administração Pública e de Empresas. McGregor e Murnane (2010), por exemplo, discutem tal problema à luz dos estudos em Consumo, no Canadá. Os autores abrem uma seção inicial no texto para apontar que, infelizmente, estudantes usam Metodologia quando querem abordar Método e tal erro concretiza-se em função de desconhecimento teórico e filosófico. Assim, os autores definem Metodologia a partir de uma perspectiva mais filosófica (a de reflexão do corpo do conhecimento), sendo Método uma perspectiva mais prática relacionada aos procedimentos técnicos na condução de uma pesquisa (o como fazer).

\section{O USO DE MANUAIS NA FUNDAMENTAÇÃO TEÓRICA}

Embora tenha diminuído o número de citações a manuais de autores como Idalberto Chiavenato e Philip Kotler em artigos avaliados em congressos, ainda encontramos, em alguns textos, esse tipo de citação. Quintella e Bogado (2004) destacam o uso de manuais em dissertações, apresentando Chiavenato como um dos autores mais citados naqueles estudos analisados pelos autores. O estudo de Cavassani, Cavassani e Biazin (2006) exemplifica como que em um congresso (momento em que os textos podem estar em construção) o uso de manuais estrutura teoricamente alguns trabalhos de pesquisa.

Mesmo em periódicos reconhecidos no campo de Administração e Administração Pública, é possível encontrar o uso de manuais. Por exemplo, o estudo de Vieira e Tiboia (2005) cita Kotler (livro Administração de Marketing) algumas vezes em um texto publicado na Revista Contemporânea de Administração - A2. Mesmo que o pesquisador Valter Afonso Vieira seja um reconhecido pesquisador quantitativo em Marketing, nesse trabalho, deu-se o uso de um manual para ajudar na construção da fundamentação teórica.

Os manuais são importantes na prática pedagógica ao estruturar tópicos em forma de capítulos, possibilitando uma leitura mais fluida para discentes de graduação, e não podemos negligenciar a importância dos manuais na construção do conhecimento. Todavia, ao fazer pesquisa com 
rigor científico, não consideramos como possibilidade a utilização de manuais como base teórica.

O não uso de manuais não é apenas uma regra que foi imposta e que deve ser seguida. Bartunek, Rynes e Ireland (2006) discutem que no processo de fundamentação teórica de um bom texto deve haver, de alguma forma, o questionamento de alguns conceitos entendidos como verdades em determinada teoria ou quanto ao objeto ou sujeitos analisados, de maneira que tais questionamentos possam convidar o leitor à reflexão. $\mathrm{E}$ entendemos que não é por meio de um manual que esta reflexão teórica acontecerá.

No nosso ponto de vista, manuais em pesquisas acadêmicas podem ser usados na explicação do percurso metodológico ao informar os procedimentos adotados no desenho da pesquisa, até porque, como aponta Daft (1983), as decisões de pesquisa não são lineares. Assim, apresentar o método à luz de referências estruturais é uma estratégia a ser considerada nas pesquisas científicas. Todavia o manual inviabiliza a possibilidade de reflexão teórica, conforme discutida por Bartunek, Rynes e Ireland (2006).

Há, ainda, um segundo problema relacionado à fundamentação teórica: o excesso no uso de tópicos para listar e discutir assuntos em um texto. Mesmo em textos em artigos de revistas B1 e B2, algumas vezes, deparamo-nos com artigos que abusam do uso de tópicos em uma comunicação que deveria ser dissertativa. Tópicos podem ser transformados em quadros ou esquemas analíticos para que o texto não seja prejudicado. Conforme aponta Daft (1983), uma das formas de prender a atenção dos leitores é construindo um texto que perpassa a ideia de história contada - e os tópicos não ajudam no enredo dos fatos, apenas, na estrutura da história. Assim, mesmo que pareça intersubjetivo o entendimento do não uso de manuais, verificamos, na prática (enquanto avaliadores), a presença dos manuais na fundamentação teórica, bem como textos que exageram no uso de tópicos. $\mathrm{E}$, assim, entendemos que ainda há a necessidade de reflexão tanto com relação ao uso de manuais quanto na utilização dos tópicos em textos dissertativos no nosso campo. 


\title{
A ECONOMIA DE INFORMAÇÕES NAS CONSIDERAÇÕES FINAIS / CONCLUSÕES DO ESTUDO
}

\author{
"É hora de acabar logo isso!" \\ "Não tem mais espaço..." \\ "Vou resgatar o objetivo e finalizar."
}

Por diversas vezes essas três frases já foram lidas ou escritas em e-mails pelos nossos pares ou por alunos de pós-graduação. Elas, parcialmente, justificam-se, mas não se sustentam quando se reflete sobre a relevância do estudo e nas cinco dimensões apresentadas por Das e Long (2010). As "Considerações Finais" ou as "Conclusões do Estudo" é parte do trabalho que os(as) autores(as) têm maior liberdade ao apresentar seus posicionamentos no texto, inclusive, pessoais e ideológicos. Entretanto, em muitos textos, essa parte parece ser apenas uma regra estrutural a ser seguida na pesquisa científica, ao terminar um relatório de pesquisa, conforme identificamos a partir da nossa percepção nos trabalhos de Fernandes, Fonseca e Cunha (2018) e Mendes (2018). São nas "Considerações Finais" que os(as) autores(as) resgatam mais que o problema de pesquisa, mas, também, a relevância da pesquisa (i) ao sugerir novas questões de pesquisa; (ii) ao apresentar implicações teóricas; e, (iii) ao discutir as implicações gerenciais não se esquecendo da conexão de uma pesquisa com a prática gerencial, mesmo na Administração Pública.

Embora o número de páginas esteja se esgotando de acordo com o formato de determinado periódico ou congresso e também se tenha um esgotamento físico típico da finalização de um relatório de pesquisa, os(as) autores(as) devem reforçar a relevância do estudo por meio do impacto dos resultados da pesquisa nas teorias já existentes e na prática gerencial. $\mathrm{Na}$ nossa experiência de autoria e coautoria, temos valorizado mais as "Considerações Finais" que a "Fundamentação Teórica" quando temos de realizar cortes no texto para alcançar um número máximo de caracteres ou palavras.

Nossa economia na base teórica dá-se em parágrafos menores e com autores(as) que orientam teoricamente a relação do objeto ou do tema de 
estudo. Assim, não há economia de teoria ou de argumentos, há economia de sentenças grandes quando se extrapola a quantidade máxima de caracteres ou de páginas. E quanto à forma de construir sentenças, pesquisadores e pesquisadoras americanos usam dessa estratégia. Assim, reduzindo sentenças, ganhamos caracteres ou páginas nas "Considerações Finais". Entendemos que muitos estudos carecem de reflexão sobre essa última seção do trabalho, uma vez que são deixadas de lado reflexões importantes sobre a utilidade de um estudo - seja para a teoria, seja para a prática gerencial.

\section{DESLIZES NA UTILIZAÇÃO DE MÉTODOS}

Ao discutir os outros seis deslizes na mesa do bar, identificamos que "Economia de Argumentos na Apresentação do Método", "A limitação de Inferência Estatística no uso de Estatística Descritiva", "Não Atendimento de Pressupostos de um Método", "A Seleção da Amostra", "Nomear um Método da Moda e usar um Método Tradicional" e "Desconsiderar as Limitações da Pesquisa e do Método" estariam relacionados ao Método em uma comunicação do tipo científica.

É interessante que, ao agregar os itens nas três dimensões aqui propostas, esta dimensão (Deslizes na Utilização de Métodos) foi a que absorveu mais itens (seis). Essa proposta analítica, de alguma forma, vai ao encontro dos achados de Falaser, Ferreira e Canela (2016), que identificaram problemas relacionados ao Método como o maior responsável na rejeição de artigos em periódicos em Administração Pública e de Empresas no Brasil. Os seis deslizes frequentes relacionados ao Método são descritos a seguir.

\section{A ECONOMIA DE ARGUMENTOS NA APRESENTAÇÃO DO MÉTODO}

Entre quatro dimensões analisadas por Barley (2006), no que diz respeito ao fato de um artigo ser interessante, a descrição do Método é uma das características importantes na apresentação de resultados de uma pesquisa. Embora Barley discuta a inovação na utilização dos métodos como estratégia para angariar maior atenção de leitores(as), fica implícito, naquela discussão, a importância de uma descrição detalhada pertinente ao processo de pesquisa, seus recortes e escolhas dos autores. 
Em contexto brasileiro, o trabalho de Falaser, Ferreira e Canela (2016) aponta a seção "Método" nos trabalhos em revistas brasileiras como uma das seções mais problemáticas de um texto, levando, muitas vezes, à rejeição. Os autores realizaram um survey com 82 editores e editoras-chefes de revistas no Brasil para identificarem os gargalos de pesquisas e suas rejeições nos periódicos. Os resultados apontam que a seção Método foi aquela que mais contribuiu para a rejeição de artigos tanto no Desk Review quando na avaliação dos pares. Esses achados reforçam aqueles apresentados por Byrne (2000). O argumento de Falaser, Ferreira e Canela (2016) torna-se robusto quando exemplificamos, a partir dos trabalhos de Mendes (2018) e Fiori e Bezerra (2018), tal economia de argumentos nesses textos já publicados.

Enquanto avaliadores, muitas vezes, rejeitamos artigos em função da economia de informações apresentadas no Método. Como validar uma pesquisa científica em Administração Pública e de Empresas se não existem aspectos claros relacionados à coleta de dados, à escolha dos sujeitos e ao recorte da pesquisa ou, ainda, sem clareza dos procedimentos relacionados à análise de dados e aos pressupostos de um método? Quando essas perguntas aparecem na análise de um texto, enquanto avaliadores, a possibilidade de rejeição do artigo aumenta consideravelmente, até porque os resultados que seguem não têm robustez científica. Depois de ler o "Resumo" de um texto, seguimos para o Método. Caso essa seção não esteja robusta, não faz sentido avaliar Resultados, Implicações Teóricas e Gerenciais. Se não fica evidente o rigor e a robustez científicos, faz sentido analisar todo o texto? Consideramos que não.

Na perspectiva da Filosofia, um método tem por objetivo descrever, de maneira aprofundada, um processo que garanta validade dos resultados (ABBAGNAMO, 2007), para, assim, estabelecer uma verdade científica (JAPIASSÚ; MARCONDES, 1996). Logo, não se deve escrever tal seção resumindo informações que descrevem o processo de "fazer ciência" de maneira robusta e criteriosa. Consideramos que é melhor pecar pelo excesso, tendo de, posteriormente, retirar informações que avaliadores(as) ou editores(as) considerem não impactar no texto, do que pecar pela falta de 
informações na seção "Método" em um trabalho. E existem manuais e fóruns específicos em revistas brasileiras (RAE, RAUSP e RAEP) e internacionais (Academy of Management Journal) que já discutiram o passo a passo de alguns métodos utilizados em Administração com o objetivo de contribuir na realização das pesquisas científicas no campo.

\section{A LIMITAÇÃO DE INFERÊNCIA ESTATÍSTICA NO USO DE ESTATÍSTICA DESCRITIVA}

Os métodos estatísticos são descritivos ou inferenciais. O objetivo principal de um método descritivo é resumir dados, enquanto que, nos métodos inferenciais, o objetivo é a generalização de resultados com base na probabilidade (AGRESTI; FINLAY, 2012). É frequente a utilização de métodos descritivos (Estatística Descritiva ou Gráficos) em estudos no Campo de Administração Pública e de Empresas no Brasil, principalmente em congressos, como pode ser verificado nos estudos de Silveira et al. (2010) e Rosa, Fagundes e Paulo (2017). Todavia o método descritivo só é válido para determinado banco de dados (amostra). Assim, se fossem coletados outros dados, os resultados poderiam ser diferentes. Já a inferência estatística constitui o principal método utilizado pelos pesquisadores para inferirem conclusões para uma população (LEVIN, 1987).

Tanto os Gráficos (Pizza, Barra, Box Plot, Histograma, etc.) quanto a Estatística Descritiva (Média, Mediana, Moda, Frequência, Proporção, etc.) têm como objetivo resumir as informações de um banco de dados e não têm a força de uma pesquisa confirmatória. A Estatística Descritiva é uma primeira etapa na análise de dados, porém o pesquisador não deve se limitar a este primeiro passo em uma pesquisa do tipo quantitativa, visto que em muitos casos apenas a análise gráfica ou numérica pode induzir resultados equivocados nas conclusões por parte dos(as) pesquisadores(as).

Uma análise confirmatória dos dados (Teste de Hipóteses) seria um método mais robusto para extrair conclusões e ajudar na tomada de decisão em organizações públicas ou privadas quando analisados na perspectiva das implicações gerenciais e teóricas de uma pesquisa aplicada. Ainda assim, o pesquisador deve zelar pela parcimônia ao escolher métodos es- 
tatísticos. Métodos estatísticos complexos dificultam a assimilação, compreensão e comunicação de resultados. Todavia, embora consideremos a necessidade da parcimônia nas comunicações científicas, a Estatística Descritiva oferece poucas possibilidades de análise que se limitam à não geração de generalização.

\section{NÃO ATENDIMENTO DE PRESSUPOSTOS DE UM MÉTODO}

Ao contrário daquilo que questionamos anteriormente (a utilização de manuais na fundamentação teórica), aqui advogamos a necessidade do uso dos manuais que descrevam e exemplifiquem métodos no sentido de evidenciar a robustez e o rigor de uma comunicação científica. No decorrer dos anos como avaliadores, temos identificado certas negligências na utilização de alguns métodos, sejam eles qualitativos ou quantitativos. Aqui utilizamos um método qualitativo (Focus Group) e outro quantitativo (Teste Anova) para exemplificar o não atendimento de pressupostos na utilização de métodos. O não atendimento de pelo menos um dos pressupostos de um método inviabiliza os resultados apresentados posteriormente e coloca em dúvida o rigor dos procedimentos metodológicos.

\section{O CASO DO FOCUS GROUP}

Alguns estudos na área de Marketing usam os Grupos de Foco para entenderem percepções, intenções, comportamentos de compra ou de boicote dos consumidores. Os Grupos de Foco têm seu uso nas pesquisas de mercado e também nas investigações científicas em função de ter surgido em pesquisas da área de Marketing após a Segunda Guerra Mundial (MORGAN, 1997). Nos estudos que utilizam Grupos de Foco é possível identificar o não atendimento de dois pressupostos de acordo com alguns manuais (MORGAN, 1997; MALHOTRA, 1999; VERGARA, 2005), são eles: (i) o número mínimo de grupos e (ii) as características do moderador escolhido para condução dos trabalhos em um grupo. Já Dias (2000) e Silva, Veloso e Keating (2014) discutem a importância do planejamento de um grupo focal e o processo de moderação e análise de dados, mas nem sempre os pressupostos são atendidos ou descritos. Por exemplo, os estudos de Modanez et 
al. (2009) e Mashorca et al. (2016) apresentam o uso do método, todavia não discutem aspectos relacionados ao planejamento e moderação dos grupos ou o número mínimo de grupos e participantes em cada grupo. Logo, esses estudos não comunicam o atendimento dos pressupostos já discutidos na literatura relativa a esse método.

No que diz respeito à quantidade de grupos, Morgan (1997) compreende que no mínimo dois grupos são necessários, sendo que Malhotra (1999) também sugere essa quantidade mínima. Já Vergara (2005) aponta que três a cinco grupos são necessários e que um número superior a cinco grupos pode não gerar novos insights. Não existe um postulado no tocante a um número mínimo, mas os autores compreendem que dois grupos são necessários, até para comparar os grupos posteriormente. Assim, um só grupo pode apresentar resultados singulares que não representem uma realidade investigada.

Da mesma forma, informações relativas ao perfil de um moderador não podem ser negligenciadas de acordo com Malhotra (1999) e Morgan (1997). Parece haver certa negligência de autores(as) neste aspecto, talvez, por desconhecerem os detalhes desse método ou por faltar espaço físico nos textos. Informar na seção Método o perfil do moderador pode parecer desnecessário; todavia, pode ajudar no entendimento de que não houve um direcionamento na condução do grupo de acordo com percepções e ideologias de um moderador - principalmente se considerados temas quentes como Política, Aborto, Descriminalização das drogas e Desarmamento. Ao conduzir um Grupo de Foco, consideramos que esses dois pressupostos devam ser atendidos, conquanto existam publicações em periódicos B1 que os desconsideraram no processo de comunicação do relatório de pesquisa, conforme foi verificado nos estudos de Modanez et al. (2009) e Mashorca et al. (2016).

\section{O CASO DO TESTE ANOVA}

O Teste Anova (Análise de Variância) é utilizado para comparar médias de dois ou mais grupos diferentes (AGRESTI; FINLAY, 2012), sendo o método mais utilizado na Ciência para comparar grupos, desde, (i) na área de Saú- 
de, a verificação de diferença entre o placebo - pílula de açúcar - e um novo medicamento (BERQUÓ; SOUZA; GOTLIEB, 1981); (ii) até em Marketing, para verificar o comportamento do consumidor quanto ao boicote a partir da negligência de aspectos relacionados à responsabilidade social corporativa (CRUZ, 2017).

A Análise de Variância é muito utilizada para determinar se as médias da amostra têm diferenças significativas ou se essa diferença ocorre em função de uma flutuação aleatória (STEVENSON, 1986). Todavia, para ser um método científico efetivo, deve-se garantir três pressupostos básicos: (i) Homocedasticidade - as populações devem ter variâncias iguais; (ii) Normalidade - as amostras devem ser extraídas de populações com distribuição normal de probabilidade; e (iii) Independência - as amostras devem ser aleatórias e independentes entre si.

O trabalho de Silva et al. (2014) utiliza-se da ANOVA para discutir a variável motivação entre alunos dos cursos de Administração e Direito, mas não apresenta na seção Método o atendimento aos pressupostos de Independência, Homocedasticidade e Normalidade. Da mesma forma, ao problematizar algumas tendências empreendedoras e a questão do gênero na escolha profissional no curso de Administração, Peñaloza, Diógenes e Sousa (2008) não discutem tais pressupostos, além de apresentarem uma análise fatorial com variáveis ordinais (Escala de Likert) ao invés do uso da Teoria de Resposta ao Item (TRI). Assim, esses dois trabalhos não informam ao leitor o atendimento aos pressupostos de Independência, Homocedasticidade e Normalidade, colocando em xeque a robustez dos resultados e das análises ali apresentadas.

O pressuposto da Homodesticidade (homo = igual; cedástico = variância) parte do princípio que as variâncias devem ser constantes (GUJARATI, 2000). A Variância é uma estatística que serve para medir a dispersão dos dados (KENNEDY; NEVILLE, 1986). Nesse caso, o pressuposto da Homocedasticidade garante que a dispersão do "Grupo 1" seja igual à dispersão do "Grupo 2", que deve ser igual ao "Grupo 3", e, assim, para os demais grupos caso existam. Para verificar se esse pressuposto foi atendido (ou não), são utilizados os testes de Levene (BROWN; FORSYTHE, 2012), 
Bartlett (MONTGOMERY, 1984; KENNEDY; NEVILLE, 1986) e Cochran (TOMAKEN; SERLIN, 1986). Para os três testes, o resultado aceitável é a não rejeição da hipótese nula. Caso esse pressuposto seja violado, existem três abordagens possíveis: (i) transformação nos dados - logaritmo, exponencial, recíproca, raiz quadrada ou arcsen (CHARNET et al., 1999, p. 133); (ii) método não paramétrico - não se analisa o parâmetro da média, mas compara os dois grupos ou mais usando toda a distribuição dos dados; ou (iii) Teste de Welch - teste de igualdade das variâncias na presença de variâncias desiguais (WELCH, 1951).

Já o pressuposto da Normalidade verifica se a variável resposta tem distribuição normal de probabilidade (GUJARATI, 2000). Para verificar esse pressuposto, existem diversos testes, sendo os mais utilizados os testes de Shapiro-Wilk, Anderson-Darling, Kramer-VonMises e Kolmogorov-Smirnov (RAZALI; WAH, 2011). Esses testes verificam a hipótese nula de normalidade (GUJARATI, 2000); ou seja, se a distribuição não for normal, não é possível utilizar a Anova. Como medida alternativa, caso o pressuposto da Normalidade não seja atendido, tem-se (i) a utilização de uma transformação nos dados - logaritmo, exponencial, recíproca, raiz quadrada ou arcsen (CHARNET et al., 1999, p. 133); ou, (ii) uma abordagem não paramétrica - o teste de Kruskall-Wallis (BRESLOW, 1970).

O terceiro pressuposto para utilização da Anova é o de Independência, ou seja, verificar se as observações ou unidades amostrais são independentes. A verificação desse pressuposto ocorre por meio do conhecimento de como os dados foram coletados; isto é, conhecer o planejamento da amostra e a definição das etapas de coleta de dados (CHARNET et al., 1999). Os testes para verificar o pressuposto de Independência são pouco comuns, mas Montgomery (1984, p. 89) recomenda gerar um gráfico dos resíduos do modelo Anova contra o tempo.

Gerar os gráficos dos resíduos a partir da ordem em que os dados foram coletados ajuda a detectar a correlação entre as unidades amostrais. Assim, o que se espera desses gráficos é uma ausência de padrão (aleatoriedade). A tendência de ter dados sequenciais positivos ou sequenciais negativos indica correlação entre as observações. A Figura 2 apresenta as 
situações 1 e 2 para ajudar a ilustrar o argumento de Montgomery (1984). Nesta base de dados, a situação 1 evidencia que, em relação ao tempo, as observações foram aleatórias; e, na situação 2, foi identificado um padrão. Todavia, para toda a base de dados, prevalece a não identificação de um padrão.

Figura 2 Resíduos do Modelo Anova contra o tempo para verificação do pressuposto de Independência

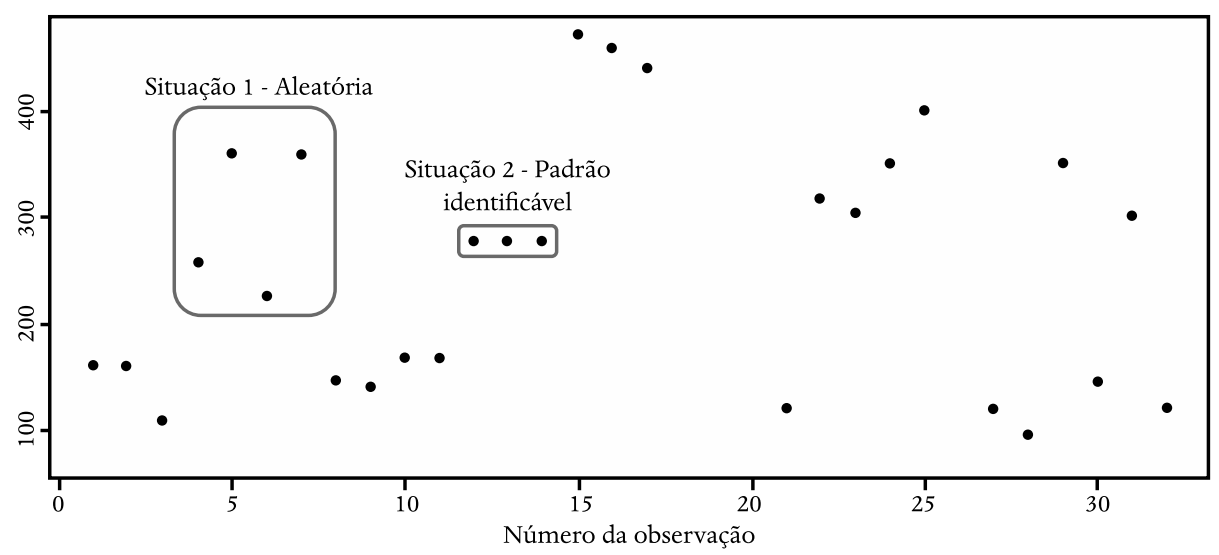

Fonte: Elaborado dos autores.

É interessante perceber que alguns autores até dominam o conhecimento relativo aos pressupostos da Anova, como se verifica no trabalho de Gebin et al. (2015). Nesse texto, os autores colocam como limitação do estudo a não realização da análise de resíduos, evidenciando o não atendimento da verificação dos pressupostos. De acordo com os autores: "O trabalho não apresentou a análise de resíduos da regressão, o que não possibilitou a verificação dos pressupostos: normalidade, independência e homocedasticidade dos erros. Para trabalhos futuros, analisar-se-á os resíduos da regressão" (GEBIN et al., 2015, p. 7). Neste trabalho, houve um erro grave de não atendimento dos pressupostos em função dos autores reconhecerem a falha em relação ao método. Tal falha inviabilizaria a apresentação dos resultados daquele estudo. 


\section{A SELEÇÃO DA AMOSTRA}

Uma das perguntas que um dos autores mais recebe de pesquisadores(as) e estudantes de Administração é: "Esse tamanho da amostra é suficiente?". Existem algumas variações desta mesma pergunta: "[...] já tenho mais de $60 \%$ dos dados da população entrevistada na minha amostra. Isso já é suficiente?”; “[...] já entrevistei mais de 200 pessoas. Isso é suficiente?”; “[...] qual o tamanho mínimo da amostra para os meus resultados serem científicos?”. Para responder a essas perguntas é necessário ter uma noção mínima de amostragem. Amostra é subconjunto de uma população-alvo (OTT et al., 1992; HEERINGA; WEST; BERGLUND, 2010) e vamos dividir esse conceito a partir de dois elementos: (i) amostra não probabilística e (ii) amostra probabilística - que pode ser chamada de representativa, pois há possibilidade de generalização de resultados para toda a população.

Essas perguntas apresentadas anteriormente não fazem sentido, pois uma amostra representativa tem maior relação com o método de coleta de dados do que com o tamanho da amostra (FOWLER-JR, 2009). Para ser representativa, todos os elementos da população-alvo devem ter chances de ser selecionados (HENRY, 1990; DATTALO, 2008). Nem todo indivíduo participará de uma amostra, mas todo indivíduo deve ter a chance de ser escolhido. Assim, o tamanho da amostra está relacionado à precisão de suas estatísticas e não com suas representatividades. Uma amostra com $98 \%$ de respostas pode ser viciada, enquanto uma amostra pequena que represente $10 \%$ da população pode ter ausência de viés e, assim, maior representatividade (SEIFE, 2012). O estudo de Sampaio, Oliveira e Oliveira (2014) propôs-se a discutir a importância da Estatística na fidelização de clientes, mas comete alguns erros relacionados à representatividade e planejamento amostral. Os autores não deixam claro se o estudo tem ou não representatividade na amostra (por conveniência ou aleatória), tampouco descrevem o planejamento amostral.

O método de coleta é a rotina de procedimentos adotados para selecionar os indivíduos de uma amostra. Para ter uma representatividade, deverá ter, obrigatoriamente, um sorteio aleatório dos indivíduos que compõem esta amostra com base na população (HENRY, 1990). O que ocor- 
re com frequência nos estudos em Administração Pública e de Empresas é a utilização da amostra por conveniência. Um exemplo comum é criar um formulário, via Survey Monkey ou Google Drive, disponibilizando, por conveniência, o instrumento de coleta de dados. Perceba-se que neste caso não há planejamento amostral, havendo somente a disponibilização de um hiperlink para qualquer pessoa responder. Por exemplo, Santos et al. (2015) propuseram-se a realizar um estudo para destacar a importância do uso da Estatística pelas empresas, mas, mesmo nesta proposta de pesquisa, trabalhou-se com amostragem por conveniência. Além disso, o estudo não especificou a população-alvo. Logo, como analisar os resultados deste estudo, em termos de representatividade, se não foi apresentada a população?

O Planejamento Amostral é importante porque garante a representatividade e a capacidade de generalizar os resultados (AGRESTI; FINLAY, 2012). Ao invés de disponibilizar um link, o pesquisador deveria, idealmente, sortear indivíduos com características semelhantes para cada grupo (SEIFE, 2012) e depois enviar o questionário para grupos com perfis que representariam um universo. Conforme apontam Agresti e Finlay (2012), existem métodos para espalhar a amostra na população, como: (a) amostra estratificada; (b) amostra por conglomerados; (c) amostra sistemática; e, (d) amostra proporcional ao tamanho.

Mesmo tendo conhecimento das limitações e restrições orçamentárias do "fazer pesquisa" no Brasil, estatisticamente, entende-se que esses dois elementos não podem ser usados como justificativas para uma pesquisa que negligencie o rigor da coleta e análise de dados, visto que existem autores na pesquisa quantitativa que criticam esse tipo de coleta de dados: "Garbage in. Garbage out." (SAATY; PENIWATI, 2013). Em outras palavras, mesmo que uma pesquisa quantitativa possa usar de um modelo matemático muito sofisticado, se a coleta de dados deixar a desejar, os resultados serão insatisfatórios.

Para justificar falhas no planejamento amostral, o estudo de Santos et al. (2015) apresentou como argumento a falta de tempo das empresas para participação na pesquisa. Os pesquisadores não teriam de reavaliar o planejamento com relação à coleta de dados para que o problema do tempo não 
se construísse como um problema de planejamento amostral? Entendemos que a falta de tempo não pode ser um problema, pois isso evidencia a negligência quanto ao planejamento amostral. Talvez, essa falta de tempo seja reflexo das exigências dos programas de pós-graduação e escolas que pressionam docentes a publicar. O trabalho de Santos et al. (2015) que foi apresentado em um congresso (que tem datas para submissão), essa suposição pode fazer sentido para explicar tal negligência com o planejamento amostral.

Consideramos, agora, outro aspecto relacionado à seleção da amostra e que, muitas vezes, é negligenciado nos estudos em Administração Pública e de Empresas: a apresentação dos critérios de inclusão e exclusão de unidades amostrais. Tais critérios são as informações exigidas em textos científicos para oferecer maior transparência na seleção dos sujeitos (MCMAHON, 2002) e seu detalhamento na seção Método contribui para aumentar o poder de transparência dos resultados de uma pesquisa.

NOMEAR UM MÉTODO DA “MODA” E USAR UM MÉTODO TRADICIONAL Aqui apresentamos como exemplo do modismo no uso de novos métodos, a Netnografia e a Grounded Theory. Estendemos que esses dois métodos de pesquisa qualitativa poderiam ser melhor utilizados em alguns trabalhos no Brasil. E esses deslizes acontecem, algumas vezes, em função de alguns avaliadores terem conhecimento no que tange à teoria ou ao objeto da pesquisa, mas não com relação ao método. Se há a escolha de um método novo no campo de conhecimento, é necessário que se busque nas fontes originais (geralmente em inglês) os detalhes que garantam o rigor do método e sua aplicação no estudo a ser conduzido. E, se o conhecimento da língua é uma variável que limita o entendimento profundo de um novo método, é prudente que se aguarde uma tradução com revisão técnica.

\section{O CASO DA NETNOGRAFIA E DA OBSERVAÇÃO NÃO PARTICIPANTE}

O estudo de Cruz, Pinto e Oliveira (2017) aponta para um interessante problema que se tem sucedido com o emprego do termo Netnografia em estudos conduzidos via plataformas digitais: usar Netnografia ao invés de 
Observação Não Participante. Como a Netnografia é um método que tem chamado atenção de pesquisadores em função da agilidade na coleta de dados e por ser uma estratégia de coleta de dados eficiente na perspectiva financeira, tem sido recorrente o emprego desse método de maneira equivocada. Por exemplo, o trabalho de Silva (2010) evidencia que foi realizada uma análise das postagens e, depois, entrevistas por e-mails com quatro participantes, não destacando a interação da pesquisadora com a comunidade. Assim, não se pode entender que foi conduzido um estudo netnográfico. $\mathrm{O}$ que se pode afirmar para esse estudo é que houve uma análise de postagens por meio de observação não participante no ambiente on-line. O estudo de Oliveira, Toledo e Lopes (2013), embora posterior ao de Silva (2010), é ainda mais problemático e incompleto ao não apresentar nem os poucos detalhes relacionados à Netnografia quando comparado ao estudo de Silva (2010).

Enquanto Método, a Netnografia é rigorosa, assim como a Etnografia em seus procedimentos de campo; e, enquanto estratégia de coleta de dados em uma pesquisa do tipo qualitativa, vai além do simples fato de copiar e colar informações em um documento eletrônico (KOZINETS, 2010; CRUZ; PINTO; OLIVEIRA, 2017). A Netnografia pressupõe interação de um ou mais pesquisadores(as) em uma comunidade a fim de obter informações aprofundadas de determinado grupo. Quando são seguidos os passos apresentados por Kozinets, principalmente considerando o processo de interação com os participantes de uma cibercultura, há possibilidade de entender os procedimentos metodológicos como Netnografia. Caso contrário, será apenas uma técnica de coleta de dados por Observação Não Participante no ambiente on-line, usando outros métodos de análises como Estudo de Caso, Análise de Conteúdo, Análise de Discurso ou até História de Vida.

\section{O CASO DA UTILIZAÇÃO DA GROUNDED THEORY}

O trabalho de Trocolli (2014) evidencia alguns erros que pesquisadores cometem ao classificarem suas investigações como Grounded Theory. Para a autora, existem pesquisadores que referem usar da Grounded Theory para confirmar seus achados e construir a teoria. Todavia Trocolli questiona as 
evidências metodológicas não apresentadas pelos pesquisadores naquelas contribuições científicas, bem como a teoria gerada. Por exemplo, a autora critica o estudo de Cruz e Zouain (2008) ao declarar que os autores não geraram teoria. E, de fato, em tal trabalho, não há evidência de geração de teoria e de clareza nos procedimentos da coleta e análise de dados na utilização da Grounded Theory.

Conforme discutido anteriormente, a utilização de manuais na condução da pesquisa e na apresentação dos resultados aos avaliadores e leitores, parece ser aceitável. Por exemplo, existem tanto livros (GODOI; BANDEIRA-DE-MELLO; SILVA, 2006) quanto artigos (BIANCHI; IKEDA, 2008) que discutem a Grounded Theory na área de Administração Pública e de Empresas. Às vezes, parece haver entusiasmo, por parte de alguns autores, ao usar métodos menos usuais e novos. Ainda que se opte pela inovação de um método, é necessário seguir o rigor do método. Nessa perspectiva, tanto a Grounded Theory quanto a Netnografia são métodos qualitativos com etapas bem-definidas e com rigor metodológico que garante a validação dos resultados e teorias discutidas. Não deixar claro o rigor do método é arriscar uma rejeição em um periódico com um bom quadro de avaliadores(as). Mais que a rejeição, é arriscar apresentar uma teoria nova que não é teoria no caso da Grounded Theory.

\section{DESCONSIDERAR AS LIMITAÇÕES DA PESQUISA E DO MÉTODO}

O contato com o professor Clovis Machado da Silva (in memoriam), por um dos autores deste texto, na disciplina Seminários de Pesquisa no Doutorado em Administração na Eaesp-FGV, reforçou a importância da apresentação das limitações da utilização do método em um estudo. Todavia, ao contrário do que muitos(as) pesquisadores(as) têm o costume de fazer, o ilustre professor Clóvis defendia o argumento de que as limitações da pesquisa e do método deveriam ser apresentadas na seção do Método. Para o professor, não fazia sentido o leitor terminar o texto para, assim, encontrar as limitações do método. Assim, já no Método, seria possível entender quais eram as limitações e realizar, então, a leitura e compreensão dos resultados à luz de um conhecimento prévio das limitações de um estudo. 
Conquanto os argumentos do saudoso Clóvis Machado da Silva façam muito sentido para nós autores deste ensaio, verificamos, na maioria das vezes, as limitações serem apresentadas nas últimas linhas de um texto em vez de na seção Método. Aqui não advogamos a sequência lógica da apresentação desses argumentos, e, sim, a importância dos(as) autores(as) reconhecerem que a condução de seus trabalhos esbarrara em algumas limitações relacionadas ao método.

Por exemplo, o trabalho de Oliveira, Toledo e Lopes (2013) não discute as limitações daquele estudo, mas, sim, a limitação de um estudo bibliográfico e sua relação com um possível viés. Ou seja, os autores não relacionam a limitação da técnica utilizada à limitação daquela presente investigação, com isso, permitindo que avaliadores e leitores entendam que aquela investigação não possui limitações. Negligenciar as limitações evidencia ou (i) uma falta de reflexão dos pontos fracos da pesquisa - eles existem e é importante deixar o ego de lado; ou, (ii) o desconhecimento de um método, objeto de estudo ou de uma teoria. Consideramos que incorporar limitações dos(as) avaliadores(as) após uma avaliação blind review contribui também para tentar diminuir lacunas não identificadas pelos autores. Reiteramos que as limitações não podem negligenciar os pressupostos de um método - como apresentado por Gebin et al. (2015) - pois, se uma limitação é o não atendimento dos pressupostos de um método, a pesquisa em si já está invalidada.

\section{DESLIZES NO SENTIDO DE "FAZER CIÊNCIA"}

O "Fazer Ciência", no nosso entendimento, implica oferecer algum tipo de contribuição para uma área de conhecimento, para a análise de um objeto ou para a construção, invalidação ou confirmação de uma teoria. Nesse sentido, considerando nosso campo de conhecimento, entendemos que um trabalho que não apresenta implicações gerenciais, implicações teóricas ou que negligencia a construção de uma agenda de pesquisa não contribui para o "Fazer Ciência" em Administração Pública e de Empresas. Assim, apresentamos os três deslizes finais que compõem a dimensão Deslizes no Sentido de "Fazer Ciência". 


\section{NÃO APRESENTAR IMPLICAÇÕES GERENCIAIS}

Um estudo em Administração Pública e de Empresas é direcionado aos pares de uma grande área - Ciências Sociais Aplicadas. Ao final de muitos trabalhos não são apresentadas suas implicações. Seja na Administração de Empresas ou na Administração Pública, um trabalho sério e com rigor científico trará no mínimo algumas implicações gerenciais - sejam relacionadas ao objetivo de estudo, sejam ao tema ou sujeitos/organizações daquela investigação. Em um artigo da década de 1970, Willian G. Ryan já discutia que da mesma forma que acadêmicos em Administração consideravam suas pesquisas relevantes e clamavam por maior utilização dos resultados de suas pesquisas nas organizações, gestores ainda eram relutantes no uso dos resultados das pesquisas acadêmicas (RYAN, 1977). DeNisi (1994) também discute a importância dos impactos de um estudo na prática gerencial.

Há, atualmente, maior absorção dos resultados de pesquisa nas organizações. Todavia essa utilização ainda parece ser distante de pequenas e médias empresas. E, no contexto brasileiro, para pesquisadores(as) que muitas vezes não tiveram contato com a prática gerencial - esse é um problema real em cursos de graduação em Administração Pública e de Empresas, principalmente em instituições públicas em que o regime de dedicação exclusiva (DE) limita o contato com a prática gerencial remunerada - a reflexão sobre as implicações gerenciais pode se tornar uma difícil tarefa. Porém esse exercício deve ser realizado justamente para que o "Sentido de Fazer Ciência" seja alcançado em nosso campo. De acordo com Bartunek, Rynes e Ireland (2006), a partir de um survey conduzido com membros do conselho editorial do periódico Academy of Management Journal, uma das características que tornam um artigo mais interessante é a apresentação de implicações gerenciais. Shugan (2003) destaca que a relevância de um artigo é percebida também pelo entendimento de gestores sobre o impacto do texto em suas decisões gerenciais.

Carton e Moricou (2017) identificam, a partir de uma análise sistemática de 11 principais periódicos em Administração no mundo, as quatro dimensões relacionadas ao rigor e relevância de uma pesquisa publicada 
em Administração. Uma dessas dimensões é "Colaboração com os Gestores". Essa dimensão pode ser entendida como o impacto dos resultados de uma pesquisa na prática gerencial. Em outros termos, implicações gerenciais. Alguns dos 10 itens considerados pelos autores nessa dimensão são (a) alinhamento da agenda de pesquisa com as necessidades do mercado; (b) construção da educação em Administração com base na prática gerencial; (c) benefícios do conhecimento prático para o avanço da ciência; e (d) coprodução de conhecimento com os gestores.

Assim, espera-se que um trabalho que é resultado de uma análise de teorias e sujeitos da Administração Pública e de Empresas apresente, para gestores e gestoras, conclusões ou ideias que possam orientá-los ao exercício prático de gestão. Não se trata de um manual prescritivo, mas, sim, de uma reflexão do impacto de um trabalho científico em possíveis organizações. E, implicações gerenciais não se restringem apenas às organizações privadas. Por exemplo, Araújo e Borges (1999) apresentam e discutem as implicações gerenciais da autonomia universitária em instituições públicas de Ensino Superior.

Mas as implicações gerenciais, tão importante contribuição, como destacam Carton e Moricou (2017), nem sempre são encontradas em um artigo publicado em uma revista acadêmica na nossa área. Por exemplo, os trabalhos de Oliveira, Toledo e Lopes (2013), Silva, Bauer e Assis (2011) e Bernardo et al. (2018), publicados no periódico REMark, não explicitam as implicações gerenciais dos estudos conduzidos, deixando clara uma falta de reflexão dos autores sobre o impacto dos resultados apresentados no estudo no dia a dia de uma organização privada. Logo, na nossa percepção, tais estudos poderiam estar mais completos caso apresentassem possíveis implicações gerenciais relacionadas ao tema e objeto discutidos.

\section{NÃO APRESENTAR IMPLICAÇÕES TEÓRICAS}

Qual o impacto de um estudo científico que não apresenta implicações teóricas? Não há explicação para um texto que é publicado em uma revista científica não apresentar no mínimo uma implicação dos seus resultados ou estratégias de pesquisa na(s) teoria(a) utilizada(s) no decorrer do texto. 
Embora a teoria seja muitas vezes complexa ou formal, de acordo com Daft (1983), o porquê que se busca com uma teoria é uma importante contribuição para a Ciência, e não simplesmente os dados coletados e suas análises. Assim, um trabalho que não tem implicações teóricas está fadado a ser considerado uma comunicação qualquer, não uma comunicação científica. Assim como no item anterior, os trabalhos de Oliveira, Toledo e Lopes (2013), Silva, Bauer e Assis (2011) e Bernardo et al. (2018), publicados no periódico REMark, não apresentaram possíveis implicações teóricas a partir de seus resultados empíricos. Assim, surge uma pergunta: qual a importância desses textos para a construção do conhecimento em Marketing se não foram apresentadas implicações teóricas?

Das e Long (2010) fazem uma interessante análise ao comparar estudos qualitativos e quantitativos na construção de teorias. Para os autores, estudos qualitativos têm maior tendência de construir teorias do que estudos quantitativos. Na nossa percepção, o objetivo de um estudo científico é apresentar resultados que corroborem ou refutem teorias e resultados já apresentados em determinada área de conhecimento. Um artigo, monografia, dissertação ou tese devem relacionar os achados e resultados da pesquisa com as teorias existentes - mesmo em pesquisas do tipo exploratória sempre há uma possibilidade de conectar os resultados com teorias existentes. E se não houver a possibilidade de conexão, não seria essa uma importante implicação teórica que deve ser destacada pelo(as) autores(as)? Talvez, uma dificuldade em apresentar as implicações teóricas em estudos se construa em função de uma fundamentação teórica ainda rasa em alguns estudos. Contudo entendemos que é necessário fomentar o processo de reflexão sobre as implicações teóricas.

\section{NÃO APONTAR A POSSIBILIDADE DE AGENDA DE PESQUISA}

Entendemos que uma boa comunicação científica deve possibilitar, como resultado de um processo de rigor acadêmico em uma investigação, a apresentação de questões de pesquisa para futuros trabalhos. Um texto que não destaca a possibilidade de futuras pesquisas a partir dos resultados apresentados à comunidade de uma área de conhecimento carece de um olhar 
atento por parte dos leitores interessados em um determinado texto. Questões de pesquisa disciplinares ou interdisciplinares podem ser apresentadas como propostas a serem investigadas por outros(as) pesquisadores(as). Em outras palavras, as questões para futuras pesquisas evidenciam também a relevância do trabalho apresentado na construção de uma agenda de pesquisa relacionada ao tema, objeto ou teoria apresentada, destacando que os resultados apresentados podem não se esgotar ao final daquele texto. E, ao apontar novas questões de pesquisa, é interessante considerar os argumentos de Garman (2011) ao destacar a irrelevância de algumas investigações e problemas de pesquisa. Todavia Carton e Mouricou (2017) também apontam a dificuldade de se definir o que é relevância.

Em pesquisas do tipo exploratória maiores são as possibilidades de apresentação de futuros questionamentos a serem trabalhados em pesquisas futuras, assim, destacando a importância do tema para uma agenda de pesquisa. Porém nem sempre os(as) autores(as) explicitam novas questões para uma agenda de pesquisa. Por exemplo, o estudo de Bernardo et al. (2018) não considera a importância de futuras pesquisas. Já o estudo de Fialho et al. (2018), embora apresente uma questão para futura pesquisa, tal questão parece ser apresentada apenas como item de um check-list, visto que não é evidenciada para o leitor uma possível reflexão ao deparar-se com aquele questionamento.

\section{UMA TENTATIVA DE ENCERRAMENTO}

Tanto Carton e Mouricou (2017) quanto DeNisi (1994) destacam que os pesquisadores, ao divulgar o conhecimento produzido na área de Administração, devem fazê-lo de maneira que a escrita seja mais simples. Esses e outros argumentos apresentados no decorrer desse texto fizeram-nos adotar uma perspectiva mais próxima do leitor, mesmo sabendo que, para os acadêmicos ortodoxos, tal estratégia pode soar como inadequada ou "menos acadêmica". Assim, esse ensaio teórico não foi pensado para bolsistas de produtividade $\mathrm{CNPq}$, pesquisadores(as) ou professores(as) renomados(as) neste campo. Ficaríamos felizes se eles(as) se debruçassem sobre este texto para analisá-lo e criticá-lo. Seria gratificante ter conhecimento de 
que professores renomados, que têm nosso respeito, como Sylvia Vergara, Fernando Tenório, Manolita Correa Lima, Tânia Fischer, Eliane Brito e Delane Botelho (entre tantos outros), leram este ensaio. Todavia escrevemos para outro público: discentes de pós-graduação e recém-mestres e doutores que estão, neste momento, sofrendo com as exigências de um sistema que avalia a produção acadêmica por estratos.

Parece que o problema escondido pelos deslizes aqui apresentados se constrói com base na lógica do produtivismo acadêmico estimulado pela Capes. E, relembrando as nossas heranças no sentido de sistematizar a Ciência da Administração, Frederick Taylor parece cada vez mais presente no cotidiano dos(as) pesquisadores(as) da Administração Pública e de Empresas a partir do momento que periódicos propõem a padronização dos textos, promovendo cada vez mais a disciplinaridade por meio da justificativa "o texto não se adapta ao escopo do periódico". Essa padronização leva ao atendimento, por parte de autores(as), das regras de submissão, mas também engessa, em alguns casos, a criatividade de quem quer comunicar seus resultados de pesquisa de maneira não ortodoxa.

E na contramão deste processo, há de se ressaltar a importância do periódico Cadernos Ebape em não balizar suas publicações a partir da estrutura dos textos - que, muitas vezes, segue um olhar mais Interpretativista. Todavia a padronização é o caminho escolhido pela maioria dos periódicos, talvez, em função das exigências da Capes. Existem revistas eletrônicas A2 e B1 que cancelam a submissão porque uma figura está colorida e não em preto e branco. Eis aqui um excelente exemplo, vivido por nós autores no processo de submissão para uma revista A2, que mostra que a ideia de padronização proposta por Frederick Taylor, ainda no começo do século $\mathrm{XX}$, está presente como uma disfunção entre nós pensadores e pensadoras da Administração Pública e de Empresas. Uma vez excluído/rejeitado o texto, apenas depois de colocarmos a figura em escala de preto e branco é que o artigo foi avaliado e, posteriormente, publicado. É de fato a cor da figura ou o seu formato 300dpi que exclui inicialmente um artigo do processo de avaliação por meio de sua relevância ou escopo? Se é uma revista eletrônica, por que não se pode ter figuras ou imagens que não sejam em 
escala de cinza? Existiria custo de impressão se o periódico é eletrônico ao permitir uma imagem colorida?

A frase de resistência "Viver não cabe no Lattes!" pichada em um muro "viralizou" como meme nas plataformas digitais, em 2017, em função do modelo produtivista que a Capes impõe aos programas de pós-graduação. Neste contexto do "Publico. Logo existo", os alunos de pós-graduação são intimados a produzir conhecimento para aumentar a nota de um programa - e talvez isso explique alguns dos deslizes praticados por quem está aprendendo a fazer Ciência no nosso campo. Discentes sofrem com a pressão de publicar, tendo, inclusive, como requisito mínimo para ter o título de mestre ou doutor a publicação de pelo menos um artigo em revistas B2, B1 ou A2.

E nessa lógica de ter de publicar para conseguir qualificar ou se titular, os deslizes tendem a surgir com maior frequência. Os estudos de Canela e Pinto (2014) e Cota, Ikeda e Sbragia (2008) já discutiam anteriormente esse olhar sobre os estudantes de pós-graduação stricto sensu. E, talvez, esse próprio ensaio, no futuro, sirva como um texto que auxilie novos(as) acadêmicos(as). Contraditoriamente, essa pressão da Capes, talvez, apresente como disfunção a não produtividade - principalmente de pequenos programas de pós-graduação que ainda estão se estabelecendo em termos de conhecimento e suas experiências deixam de ser compartilhadas. E, assim, talvez, a maioria não se encaixe dentro das regras. Não seria o momento de repensar os critérios da Capes no sentido de democratizar este espaço de compartilhamento de conhecimento?

Assim, seja como avaliadores de periódicos de menor estrato, em congressos ou como docentes da pós-graduação, nossa experiência, enquanto pesquisadores, alertou-nos sobre os deslizes frequentes cometidos por alguns pesquisadores no nosso campo de conhecimento. A jornada acadêmica é repleta de caminhos sinuosos que podem conduzir aos deslizes. Esses deslizes, provavelmente, sejam frutos da dicotomia Intuição-Teoria, discutida por Moser, Mulder e Trout (2009) na Teoria do Conhecimento. Para os autores, há a necessidade de ter cuidado com a confiança depositada nas intuições, principalmente aquelas que derivam do senso comum. 
Por exemplo, embora muitos(as) pesquisadores(as) em Administração Pública e de Empresas não se preocupem com a distinção entre os termos Método e Metodologia, a Filosofia destaca a diferença entre tais conceitos - como discutido anteriormente. Portanto, parece que o uso do termo Metodologia nos estudos do nosso campo se tornou senso comum - mesmo sendo utilizado a partir de uma intuição equivocada quando analisada na perspectiva filosófica. E se, por um lado, a Administração parece carecer de teorias fortes sem influência direta de outros campos de conhecimento, por outro lado, a Filosofia, ao contrário da Administração, é robusta a ponto de interferir em outras áreas de conhecimento.

Esses deslizes geram, de certo modo, incômodo em pesquisadores(as) que têm forte formação teórica e prática em Pesquisa. Todavia tal inquietação associada ao ego presente na academia não pode contribuir para um clima de animosidade entre autores, avaliadores e ouvintes em congressos. Há, de um lado, autores que não sabem lidar com críticas, e, de outro lado, ouvintes em congressos e avaliadores que desqualificam todo um trabalho por uso de um termo que não conversa com sua ideologia teórica. Já presenciamos cenas lastimáveis em eventos por parte de professores que não conseguiam fazer um recorte em suas análises, entendendo que suas críticas estavam sendo direcionadas a alunos de mestrado que apresentavam um texto. Ao mesmo tempo, faziam considerações e exigências coerentes com uma realidade de um trabalho submetido a um periódico A1. Por sua vez, existem avaliadores(as) que não conseguem identificar equívocos básicos como os apresentados aqui no decorrer deste texto, aprovando textos que não estariam ainda prontos para serem discutidos em congressos ou publicados em periódicos.

Apresentar os 13 deslizes identificados em uma mesa de bar, por nós autores neste texto, é, de forma diferente ao que fazem alguns avaliadores em revistas e congressos, tentar contribuir para um espaço acadêmico mais prazeroso, colaborativo e de trocas. As três dimensões, formadas a partir dos 13 deslizes aqui apresentados, convergem para os resultados e análises conduzidas por alguns pesquisadores em contexto internacional (RYAN, 1977; DAFT, 1983; SHUGAN, 2003; VOSS, 2003; BARLEY, 2006; BARTU- 
NEK; RYNES; IRELAND, 2006; DAS; LONG, 2010; GARMAN, 2011; CARTON; MOURICOU, 2017 ). E, em contexto nacional, a dimensão "Deslizes na Utilização do Método" evidencia a importância do trabalho de Falaser, Ferreira e Canela (2016), sobretudo em função da nossa análise para agregar os itens às dimensões ter sido realizada antes de ter acesso ao estudo destes autores.

Entendemos que apresentar aqui as três dimensões é, por si, uma contribuição teórico-empírica. É teórica pelo fato de evidenciar, na área de Ensino e Pesquisa em Administração, que existem trabalhos sendo publicados com erros teóricos e metodológicos. Entendemos que o presente texto traz implicações práticas para estudantes de pós-graduação (e até de iniciação científica) que ainda não dominam questões referentes ao Método de um trabalho científico, bem como a forma e o conteúdo. Assim, futuras pesquisas podem apontar algumas direções, como (i) levantar bibliometricamente estudos no campo de Administração Pública e de Empresas relacionados à "forma de fazer pesquisa" e suas contribuições na área; (ii) conduzir um experimento para analisar os deslizes aqui apresentados antes e depois de um discente ser exposto ao presente texto; (iii) explorar questões relacionadas ao assédio moral no contexto de produtivismo acadêmico; ou (iv) identificar junto aos discentes de pós-graduação as principais lacunas no tocante às três dimensões aqui apresentadas.

No decorrer das nossas trajetórias, fomos duplamente contemplados com experiências fantásticas nos processos de avaliação e algumas delas se encontram neste texto, agora, como dicas de erros que já cometemos quando iniciamos nossa jornada. Contudo, em muitos casos, principalmente em periódicos de maior estrato, recebemos avaliações constrangedoras que, algumas vezes, serviram como intimidação, fazendo-nos pensar sobre o que é fazer Ciência no nosso campo de atuação. Em uma avaliação, por exemplo, recebemos a seguinte crítica: "Postura na minha terra é de galinha, não de Responsabilidade Social”. Como destacam Patrus, Dantas e Shigaki (2016), existem disfunções no processo de avaliação dos pares, sendo uma delas a imprecisão da avaliação por pessoas que seriam especialistas em determinada área de conhecimento. 
Embora Hames (2012) discuta que uma das disfunções da avaliação por pares possa ser a existência de abusos ou preconceitos de editores ou revisores, pensamos que é possível construir uma academia menos frustrante para futuros(as) pesquisadores(as) e professores(as) do nosso campo, de maneira a interromper comportamentos como o da "postura de galinha" e tantos outros que podem surgir neste momento na mente dos(as) leitores(as) ao lembrarem-se de experiências passadas. E, na nossa percepção, os editores e editoras têm desempenhado papel fundamental nessa mudança para tornar este processo mais leve e menos traumático no nosso campo de conhecimento. Assim, embora utópico, finalizamos este texto acreditando que nossas reflexões, aqui apresentadas na RAEP, possam contribuir para jovens pesquisadores(as) na condução de futuras pesquisas em Administração Pública e de Empresas. 


\section{REFERÊNCIAS}

ABBAGNANO, N. Dicionário de Filosofia. Martins Fontes: São Paulo, 2007.

ARAÚJO, M. A. D. de; BORGES, D. F. Autonomia universitária: implicações gerenciais para as instituições federais de ensino superior. RAP, Rio de Janeiro, RJ, v. 33, n. 4, 1999 p. 7-23.

BANDEIRA-DE-MELLO, R.; CUNHA, C. J. C. de A. Grounded Theory. In: GODOI, C. K.; BANDEIRA-DE-MELLO, R.; SILVA, A. B. Pesquisa Qualitativa em Estudos Organizacionais: Paradigmas, Estratégias e Métodos. São Paulo: Editora Saraiva, 2006.

BARLEY, S. R. When I write my masterpiece: thoughts on what makes a paper interesting. Academy of Management Journal, v. 49, n.1, p. 16-20, 2006.

BARTUNEK, J. M.; RYNES, S. L.; IRELAND, D. What makes Management Research interesting, and why does it matter? Academy of Management Journal, v. 49, n.1, p. 9-15, 2006.

BERNARDO, M. H. et al. Brand Love no Setor de Cosméticos: Uma Análise Comparativa das Revendedoras de uma Marca Global do Brasil e do México. Brazilian Journal of Marketing, São Paulo, SP, v. 17, n. 3, p. 19-30, 2018.

BERQUÓ, E. S.; SOUZA, J. M. P. de; GOTLIEB, S. L. D. Bioestatística. São Paulo: E.P.U., 1981.

BIANCHI, E. P. G.; IKEDA, A. A. Usos e Aplicações da Grounded Theory em Administração. Revista Eletrônica de Gestão Organizacional, Recife, PE, v. 6, n. 2, 231-248, 2008.

BISPO, M. de S.; COSTA, F. J. da. Artigos como avaliação discente em disciplinas de pós-graduação: Marcelo de Souza Bispo instrumento educativo ou subsistema de linha de montagem? Cadernos Ebape, Rio de Janeiro, RJ, v. 14, n. 4, p. 1007-1010, 2016.

BOAVENTURA, P. S. M. et al. Desafios na formação de profissionais em Administração no Brasil. Administração: Ensino e Pesquisa, v. 19, n. 1, p. 1-31, 2018.

BRESLOW, N. A generalized Kruskall-Wallis test for comparing $\mathrm{K}$ samples subject to unequal patternes of censorship. Biometrika, v. 57, n. 3, p. 579-594, 1970.

BROWN, M. B.; FORSYTHE, A. B. Robust tests for the Equality of Variances. Journal of the American Statistical Association, v. 69, n. 74, p. 364-367, 2012.

BYRNE, D. W. Common reasons for rejecting manuscripts at medical journals: a survey of editors and peer reviewers. Science Editor, v. 23, n. 2, p. 39-44, 2000.

CARTON, G.; MOURICOU, P. Is management research relevant ? A systematic analysis of the rigor-relevance debate in top-tier journals (1994-2013). M@n@gement, v. 20, n. 2, p. 166-203, 2017.

CASSUNDÉ, F. de S. A. et al. [Re]Pensando o Estágio na formação profissional dos estudantes de Administração: um estudo sobre a produção científica brasileira na área. Administração: Ensino e Pesquisa, v. 18, n. 3, p. 594-623, 2017. 
CAVASSANI, A. P.; CAVASSANI, E. B.; BIAZIN, C. C. Qualidade vida no trabalho: fatores que influenciam as organizações. In: SIMPEP, XIII, 2006. Anais... Bauru/SP: Unesp, 2006.

CHARNET, R. et al. Análise de Modelos de Regressão Linear com Aplicações. Campinas: Editora da Unicamp, 1999.

COOK, J. A.; FONOW, M. M. Knowledge and women”s interests issues of epistemology and methodology in feminist sociological research. Sociological Inquiry, v. 56, n. 1, p. 2-19, 1986.

COTA, M. F. de M.; IKEDA, A. A.; SBRAGIA, R. Lições Aprendidas no Desenvolvimento de Dissertações e de Teses em Administração. In: SEMEAD, XI, 2008. Anais... São Paulo: FEA-USP, 2008.

CRUZ, B. de P. A.; PINTO, G. V.; OLIVEIRA, V. A. de. Capturo Pokémons. "Logo Existo”. Realidade Aumentada e Consumo à Luz das Experiências dos Usuários do Pokémon Go. ReMark, São Paulo, SP, v. 16, 4, 2017.

CRUZ, B. de P. A.; ZOUAIN, D. M. Atuação de consórcios de exportação brasileiros no segmento de moda praia. RAM - Rev. Adm. Mackenzie, v. 9, n. 2, p. 11-30, 2008.

DAFT, R. L. Learning the Craft of Organizational Research. The Academy of Management Review, v. 8, n. 4, p. 539-546, 1983.

DAS, H.; LONG, B. S. What Makes Management Research Interesting?: An Exploratory Study. Journal of Managerial Issues, v. XXII, n. 1, p. 127-144, 2010.

DATTALO, P. Determining Sample Size - Balancing Power, Precision and Practicality. Oxford: Oxford University Press, 2008.

DENISI, A. From the editor. Academy of Management Journal, v. 37, 3, p. 465, 1994.

DIAS, C. A. Grupo Focal: técnica de coleta de dados em pesquisas qualitativas. Informação e Sociedade: Estudos, v. 10, n. 2, p. 1-12, 2010.

DICK, B. Reflections on the SAGE Encyclopedia of Action Research and what it says about action research and its methodologies. Action Research, v. 13, n. 4, p. 431-444, 2015.

FALASER, C.; FERREIRA, M. P. Motivos de Rejeição dos Artigos nos Periódicos em Administração. Organ. Soc. v. 23, n. 77, p. 285-306, 2016.

FERNANDES, A. R. de; FONSECA, S. E.; CUNHA, C. L. Responsabilidade Social e Influências sobre Retornos de Cotações: um estudo a cerca do Desempenho de Índices de Sustentabilidade. Revista Administração em Diálogo, v. 20, n. 1, p. 25-39, 2018.

FERREIRA, M. A. S. P. V.; CANELA, R.; PINTO, C. F. O Processo Editorial nos periódicos e sugestões para publicação. Revista de Gestão e Secretariado, v. 5, n. 2, p. 1-22, 2014.

FIALHO, C. B; ROSA, Á. F. da; GAI, M. J. P.; PAZ, A. de F. N. Empoderamento e Gênero: um estudo com mulheres que ocupam cargos de gestão em uma universidade federal. Administração em Diálogo, v. 20, n. 1, p. 01-24, 2018. 
FINI, M. I. Inovações no Ensino Superior - Metodologias Inovadoras de Aprendizagem e suas relações com o mundo do trabalho: desafios para a transformação de uma cultura. Administração: Ensino e Pesquisa, v. 19, n. 1, p. 176-183, 2018.

FIORI, F. C.; BEZERRA, C. A. Relações entre Tipos de Bolsas e Número de Publicações de Bolsistas de Iniciação Científica em Ciências Sociais Aplicadas: um estudo na Universidade Federal do Paraná. Revista Administração em Diálogo, v. 20, n. 1, p. 57-81, 2018.

FLATES, G. G. S.; SERRA, F. A. R.; MARTINS, C. A aptidão dos pesquisadores brasileiros pertencentes aos programas de pós-graduação Stricto Sensu em Administração para pesquisas quantitativas. Rausp, v. 49, n. 2, p. 384-398, 2014.

FOWLER-JR, F. J. Survey Research Methods. 4. ed. California: SAGE Publications, 2009.

GEBIN, L. G. G. et al. Análise dos determinantes do Índice Combinado das maiores seguradoras brasileiras: um estudo econométrico entre os anos de 2005 a 2014. In: SIGET, XII, 2015. Anais... Resende/RJ: AEDB, 2015.

GODOI, C. K.; BANDEIRA-DE-MELLO, R.; SILVA, A. B. Pesquisa Qualitativa em Estudos Organizacionais: Paradigmas, Estratégias e Métodos. São Paulo: Saraiva, 2006.

GUJARATI, D. N. Econometria Básica. 3. ed. São Paulo: Pearson Education, 2000.

HARDING, S. Feminism and Methodology. Blomington: Indiana University Press, Bloomington, 1987.

HAMES, I. The current state of peer review: criticisms, challenges and innovations. In: ENCONTRO DA ASSOCIAÇÃO BRASILEIRA DE EDITORES CIENTÍFICOS, 7., 2012. Anais... Florianópolis/SC: ABEC, 2012.

EERINGA, S. G.; WEST, B. T.; BERGLUND, P. A. Applied Survey Data Analysis. Florida: CRC Press, 2010.

HENRY, G. T. Practical Sampling. California: SAGE Publications, 1990.

JAPIASSÚ, H.; MARCONDES, D. Dicionário Básico de Filosofia. 3. ed. Rio de Janeiro: Jorge Zahar, 1996.

KENNEDY, J. B.; NEVILLE, A. M. Basic Statistical Methods for Engineers and Scientists. 3. ed. New York: Harper e Row, Publisheres, 1986.

KOZINETS, R. V. Netnography - Doing Ethnographic Research Online. London: Sage Publications, 2010.

LEVIN, J. Estatística Aplicada às Ciências Humanas, 2. ed. São Paulo: Harbra, 1987.

MARTINS, H. H. T. de Souza. Metodologia qualitativa de pesquisa. Educação e Pesquisa, v. 30, n. 2, p. 289-300, 2004.

MASCARENHAS, A. O.; BARBOSA, A. C. Q. Produção Científica Brasileira em Gestão de Pessoas no Período 200-2010. RAE, v. 53 , n. 1, p. 35-45, 2013. 
MASHORCA, K. S. et al. A Beleza e a Vaidade em Relação a Novos Tipos de Alimentos: Um Estudo sobre o Mercado de Nutricosméticos. Brazilian Journal of Marketing, v. 15, n. 3, p. 401-417, 2016.

MCGREGOR, S. L. T.; MURNANE, J. A. Paradigm, methodology and method: intelectual integrity in consumer scholarship. International Journal of Consumer Studies, v. 34, p. 419-427, 2010.

MCMAHON, A. D. Study control, violators, inclusion criteria and defining explanotory and pragmatic trials. Statistics in Medicine, v. 21, n. 10, p. 1365-1376, 2012.

MENDES, S. Matos. Colaboração Externa no Processo de Inovação de uma Fashion Industry. Revista Administração em Diálogo, v. 20, n. 1, p. 103-120, 2018.

MINGERS, J. Combining IS Research Methods: Towards a Pluralist Methodology. Information System Research, v. 12, n. 3, p. 240-259, 2015.

MONTGOMERY, D C. Design and Analysis of Experiments. 2. ed. Toronto: John Wileye Sons, Inc., 1984.

MORGAN, D. L. Planing Focus Groups. Newbury Park, CA: Sage Publications, 1997.

MODANEZ, P. S. et al. Segmentação Psicográfica e estilos de vida de consumidores de venda direta por catálogo. REMark, v. 8, n. 1, p. 138-163, 2009.

MOSER, P. K.; MULDER, D. H.; TROUT, J. D. A Teoria do Conhecimento - uma introdução temática. 2. ed. São Paulo: WMF Martins Fontes, 2009.

OLIVEIRA, B. A.; TOLEDO, A. C.; LOPES, E. L. Evolução da Experiência no Varejo de Serviços: um exemplo do setor de Telecomunicações brasileiro. REMark, v. 12, n. 1, p. 223-250, 2013.

OTT, R. L. et al. Statistics - a tool for the Social Sciences. 5. ed. Belmont: Duxburry Press, 1992. PAES DE PAULA, A. P. Para além dos paradigmas nos Estudos Organizacionais: O Círculo das Matrizes Epistêmicas. Cadernos Ebape, v. 14, n. 1, p. 27-46, 2016.

PATRUS, R.; DANTAS, D. C.; SHIGAKI, H. B. O produtivismo acadêmico e seus impactos na pós-graduação sirito sensu: uma ameaça à solidariedade entre pares? Cadernos Ebape, v. 13, n. 1, p. 1-18, 2015.

PATRUS, R.; DANTAS, D. C.; SHIGAKI, H. B. Pesquisar é preciso. Publicar não é preciso: história e controvérsias sobre a avaliação por pares. Avaliação, v. 21, n. 3, p. 799-820, 2016.

PENALOZA, V.; DIÓGENES, C. G.; SOUSA, S. J. A. Escolha Profissional no Curso de Administração: Tendências Empreendedoras e Gênero. Revista de Administração Mackenzie, v. 9, n. 8, Edição Especial, p. 151-167, 2008.

PIACENTINI, M. T. de. A forma em evidência: estilo e correção em trabalhos acadêmicos. In: BIANCHETTI, L.; MEKSENAS, P. (Orgs.). Teoria, Método e Escrita em Ciência e Pesquisa. Campinas, SP: Papirus, 2008. v. 1. 
QUINTELLA, H. M.; BOGADO, Savio Domingos Coube. Análise Bibliográfica e Mapeamento da produção de um grupo de pesquisa sobre o uso competitivo da tecnologia de informação. Engevista, v. 6, n. 2, p. 36-47, 2004.

RAZALI, N. M.; WAH, B. W. Power Comparisons of Shapiro-Wilk, Kolmogorov-Smirnov, Lillefors and Anderson-Darling testes. Journal of Statistical Modeling and Analytics, v. 2, n. 1, p. 21-33, 2011.

RÍMOLI, T. T.; MELO, D. de C. A Voz dos consumidores em redes sociais: proposição de um modelo eficaz de Gestão de Reclamações às empresas. Brazilian Journal of Marketing, v. 17, n.1, p. 49-64, 2018.

ROSA, T. A.; FAGUNDES, A. F. de A.; PAULO, R. R. D. Comunicação Interna: uma avaliação da Intranet Corporativa do Grupo X. In: ENANGRAD, XVIII, 2017. Anais... Brasilia/DF, EnAngrad, 2017.

SAAT, T. L.; PENIWATI, K. Group Decision Making: Drawing out and Reconciling Differences. Pittsburgh: RSW Publications, 2013.

SAMPAIO, N. A. de S.; OLIVEIRA, A.; OLIVEIRA; S. Análise Estatística para Fidelização de Clientes. In: SEGET, XI, 2014. Anais... Resende/RJ: AEDB, 2004.

SANTOS, B. M. dos et al.. A Importância e o uso da Estatística na área empresarial: uma pesquisa de campo com empresas do município de Elói Mendes - MG. In: SEGET, XIII, 2016. Anais... Resende/RJ: AEDB, 2016.

SEIFE, C. Os números (não) mentem. Rio de Janeiro: Zahar, 2012.

SHUGAN, S. M. Defining Interesting Research Problems. Marketing Science, v. 22, n. 1, p. $1-15,2003$.

SILVA, I. S.; VELOSO, A. L.; KEATING, J. B. Focus group: Considerações teóricas e metodológicas. Revista Lusófona de Educação, v. 26, n. 26, p. 175-190, 2014.

SILVA, T. M. B. da. “Não preciso de coleira eletrônica!”: um estudo sobre o movimento de resistência ao celular em blogs e comunidades virtuais. REMark, v. 9, n. 2, p. 113-136, 2010.

SILVA, T. M. B. da; BAUER, H.; ASSIS, M. A. Cibertativismo e Comunidades Virtuais: um estudo sobre o movimento Anti-Globo. REMark, v.10, n. 3, p. 84-105, 2011.

SILVA, T. L. F. da et al. A motivação no Ensino Superior: um estudo com alunos dos cursos de Administração e Direito. Journal of Management Analysis, v. 3, n. 1, p. 104-113, 2014.

SILVEIRA, A. et al. Empreendedorismo em Diferentes Tipos de Organizações: Análise da Produção Científica na Base de Dados SciELO: 2004-2008. Faces Journal, v. 9, n. 3, p. 13-32, 2010.

SPINK, P. K. O pesquisador conversador do cotidiano. Psicologia e Sociedade, v. 20 (spe), p. 70-77, 2008. 
TOMAKEN, A. J.; SERLIN, R. C. Comparision of ANOVA alternatives under variances heterogenity and specific non centrality structures. Psychological Bulletin, v. 99, n. 1, p. 90-99, 1986.

TROCOLLI, I. Ra. E os Pesquisadores Brasileiros que Praticam Grounded Theory: O que Fazem? Rev. Digita. Bibliotecon. Cienc. Inf., v. 12, n. 2, 20-37, 2014.

VIEIRA, V. A.; TIBOLA, F. Pesquisa qualitativa em marketing e suas variações: trilhas para pesquisas futuras. Revista de Administração Contemporânea, v. 9, n. 2, p. 9-33, 2005.

VIZEU, F.; MACADAR, M. A.; GRAEMLL, A. R. Produtivismo acadêmico baseado em uma perspectiva habermasiana. Cadernos Ebape, v. 14, n. 4, p. 984-1000, 2016.

VOSS, G. B. Formulating Interesting Research Questions. Journal of the Academy of Marketing Science, v. 31, n. 3, p. 356-359, 2003.

WELCH, B. L. On the Comparison of Several Mean Values: An Alternative Approach. Biometrika, v. 38, n. 3, p. 330-336, 1951. 


\section{DADOS DOS AUTORES}

\section{BRENO DE PAULA ANDRADE CRUZ` brenocruz@yahoo.com.br}

\section{Doutor em Administração pela FGV-EAESP}

Instituição de vinculação: Universidade Federal Rural do Rio de Janeiro

Seropédica/RJ - Brasil

Áreas de interesse em pesquisa: Marketing; Responsabilidade Social Corporativa; Ensino e Pesquisa em Administração.

* Departamento de Administração Pública-UFRRJ BR-465, Km 7 Seropédica/RJ 23897-000

\section{STEVEN DUTT ROSS steven.ross@unriotec.br}

\section{Doutor em Engenharia de Produção pela UFF}

Instituição de vinculação: Universidade Federal do Estado do Rio de Janeiro -

Departamento de Métodos Quantitativos

Rio de Janeiro/RJ - Brasil

Áreas de interesse em pesquisa: Avaliação de Impacto; Análise Multivariada; Visualização de Dados. 